\title{
11
}

\section{Constituting Users in Requirements Techniques}

\author{
C. Westrup \\ Department of Accounting and Finance \\ University of Manchester \\ Manchester M13 9PL, England \\ Tel: $\quad+441612754007$ \\ Fax: +441612754023 \\ E-mail: Chris.Westrup@man.ac.uk
}

\begin{abstract}
This paper explores the concepts of the "user" and "user participation" in the information systems (IS) literatures. It argues that categories such as future IS users are constituted by the processes of systems development such as requirements analysis techniques. The upshot of this argument is straightforward: qualitative research should not naively deploy categories such as users without acknowledging the considerable work that has gone into their constitution. This is not just an important academic nicety: constituting categories such as users and developers is shown to be a major concern of those engaged in systems development because it facilitates control of this process. The paper examines two well known approaches to systems development that involve users: ETHICS/QUICKethics and the Scandinavian cooperative approach, to show their constitutive effects. While agreeing that user participation is desirable, this paper makes four points that compromise many of the ambitions of user participation in systems development. First, that user participation is engaging in a political process in which issues of representation are central; second, that users (and systems developers) are categories constituted by these processes of systems development; third, that the users' ability to speak for the organization is usually limited; and finally, that users need to be wary of how information technology is represented to them by
\end{abstract}


developers. Through these arguments, this paper seeks to contribute to the issue of researching IS by showing difficulties in the very vocabularies of systems development.

\section{INTRODUCTION}

Calls for the use of qualitative research in information systems research have appeal, not least in a common recognition of shortcomings in a simple reliance on quantitative techniques. But, as we witness in so many areas of life, agreement on the shortcomings of others often conceals differences among those who agree. This paper seeks constructively to critique some categories that are used to describe systems development from a qualitative perspective to show how techniques are implicated in constituting categories such as users. This argument has important consequences for how user participation may be achieved in systems development and two well known approaches to user involvement are examined: ETHICS/QUICKethics and the Scandinavian cooperative approach. The argument here is that these approaches are one formulation of attempts to negotiate what is attributed to the technical (computers, systems developers, computer science) and the social (organizations, users, and social theory). Although user participation is important, these approaches are important resources in configuring the entities they claim to represent, be they organizations, users, computers, or developers. This is an exploration of requirements in information systems theory but the findings of this paper have practical import for situations in which requirements are being established: requirements in practice. An outline of the theoretic approach will be given before discussion of the practical and theoretic issues raised in relation to requirements analysis. This discussion paves the way for a detailed examination of how, in theory, two approaches constitute categories such as users (and developers).

\section{TECHNIQUES AND THE FORMULATION OF THE TECHNICAL AND THE SOCIAL}

Our starting point is that neither technology nor social forces (technological or social determinism) can be invoked as causal agents in the development of information systems. In contrast we propose, drawing on Latour, that they are outcomes of relations of attribution that distribute the conception of the social and the technical (Latour 1987). This implies that neither the technical (as information technology) nor the social (as organizations) have essential qualities that remain unchanging; rather, what is seen as technical and as social changes over time and in different contexts. Requirements techniques have been developed to link organizations with information technology and vice versa and those involving users will be analyzed to see how they distribute the conceptions of the social (as users, organizations and the like) and the technical (as computers, developers). One formulation of the relationship between the social and the technical is to have users as the key exponents of what the organiza- 
tion wants and what the organization does (spokespersons for the social). Systems developers are taken as spokespersons for the technical, the information technology whose workings and deployment remain unseen (see Figure 1). To determine what the users' requirements might be, they must participate in the formulation of requirements and developers must cooperate and communicate with them to produce requirements. ${ }^{1}$

\section{Social}
Users
(representing the social qua organization)

\section{Technical}

\author{
Developers \\ (representing the technical \\ qua information technology)
}

\section{Requirements Techniques \\ invoking user involvement}

Figure 1 Users and Developers as Representatives of the Social and the Technical.

One of the features of a requirements technique is that it seeks to represent and inscribe the social (qua organizations) in such a way that it becomes capable of being circulated and recombined while maintaining its inscription. For example, data flow diagrams are inscriptions of processes recognized in the social. They represent the organization and may be taken elsewhere and recombined in different forms so that developers are able to create information systems which "fit" that representation of the organization. However, each inscription is a translation of what was recognized into a different formulation. The more successful the translation, the less it is seen as such and instead we consider that we are accurately/realistically depicting what was there. When inscriptions are created that can circulate, be combined, and remain intact, then it is possible for a network of relations to be produced which link people/actors in various sites (see Figure 2). Put simply, unless these inscriptions are produced, it is extremely difficult to develop requirements and "successful" information systems.

1 This is but one formulation of these relations. Other approaches formulate the relationship as between organizations and technology; information required and requirements techniques; and social theory and computer science (see Westrup 1996). 


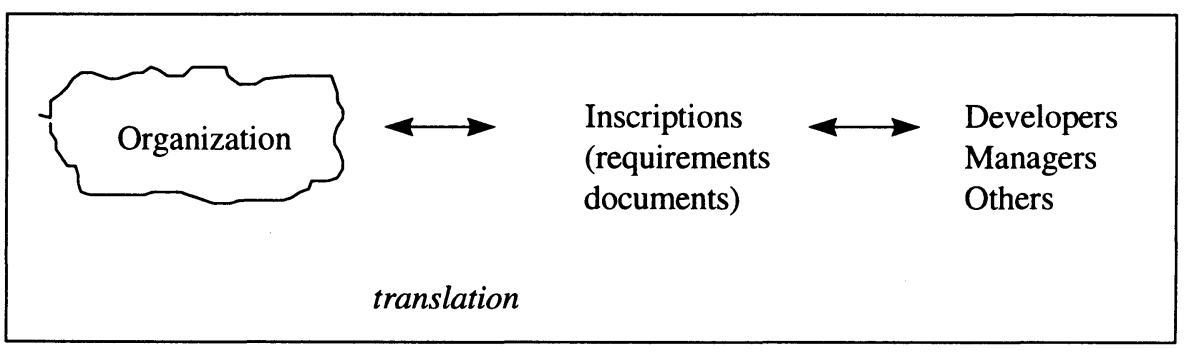

Figure 2 Requirements Specification: A Translation of an Unclear Organization into Inscriptions that may then Circulate Elsewhere.

\section{WHO ARE USERS (AND DEVELOPERS)? A PRACTICAL PROBLEM AND THEORETIC ISSUE}

Discussing requirements analysis in terms of social and the technical is rather abstract. In many situations of systems development, the categories of organization and information technology are treated as unproblematic and no requirements analysis techniques are used. However, we have a considerable literature on the failures of information technology and one outcome has been to emphasize the importance of the user and their participation in systems development. Various techniques have been created to produce conditions in which user participation is a key feature of requirements analysis. Before examining these techniques, it is important to explore the notions of user and designer and their interrelationship. When the question "what is a user" is asked, it is clear that, prior to the conception of an information system, no such category exists. In the literature on systems development, the word user is widely employed, but if an information system has not actually been implemented then the term user is, at the very least, an aspiration and does not refer to an actual state of affairs. What this demonstrates is that employing the term user is already creating a relationship between a posited information system and the social. The social is being taken as comprising of users, be they compliant, enthusiastic or recalcitrant, that are constituted by a relationship of using a potential computer system. In other words, an assumption is made manifest that the social may be described accurately in terms that relate it to a perception of the technical.

In the information systems literatures, the term user has not referred to a similar group of people. In the Garmisch conference on software engineering in 1968, users were considered to be those who used computer hardware; in other words, those who developed software for and ran computers in organizations - a category that would now be called developers (Naur and Randell 1969, pp. 40-41). In different countries it is recognized that users may refer to different groupings. The clearest distinction 
is the employment of user in the USA as opposed to Scandinavia (Carmel, Whitaker and George 1993). As Carmel, Whitaker and George put it:

An unambiguous definition of "user" is impossible. The North American reader understands "user" to mean any non-IS/technical individual in an organization who is affected by the system - this includes managers. The Scandinavian reader understands "user" to mean any operational worker who is affected by the system - this does not include managers. [p. 40]

As we find that the term user is both referential, in terms of systems development, and mutable, in terms of time and space, it invites us to consider how the user is produced.

\subsection{A Practical Problem}

The question of who or what is the user is often a very practical problem for those developing computer systems. For what we term in-house development, the question is who can speak for those who will use the system; for those developing systems, either for other organizations or as products, the problem is more acute. Grundin (1991, p. 441) refers to obstacles to user participation drawn from the experiences of developers in producing computer systems for large numbers of organizations. The first obstacle is a "challenge in identifying appropriate users and groups." For example, developers produce a product for a market that will not have users until the information system is finished and marketed. A serious problem is found in "trying to identify specific or characteristic users" when choosing one user may "seem to eliminate other possibilities." A second difficulty is "obtaining access to users." Two issues arise here: the difficulty in contacting users and the problems that arise for developers when they do meet.

Grundin also identifies problems in motivating users to become involved, especially in large scale projects being developed over a number of years or where the outcome of the project is to threaten potential user's job security. Similarly, developers also have to be motivated to become involved with users due to a lack of empathy with nontechnical computer users or differences in values or work styles or because of the "slowness and imprecision that often accompanies user involvement."

Finally, Grundin poses another problem that of "trying to find the design team." He sets this problem in the context of interface design, but the problem can equally be applied to requirements in general:

User involvement would be easier if one group had responsibility for all aspects of usability....But the "user interface," broadly defined, is not often the province of one recognizable team in a large product development company. The hardware is designed by one group, the software by another, the documentation by a third, and the training by a fourth. [p. 445]

The identification of problems such as these is not restricted to Grundin; in a widely cited study, Curtis, Krasner and Iscoe (1988) came to similar conclusions when they interviewed developers on large software development projects. 
Although these studies show that user participation is a pressing problem for developers of computer systems, it raises issues of theoretic importance. Given the difficulty in identifying, isolating and communicating with users, how are users constituted as a group? Second, Grundin also shows that developers are not a homogeneous entity and that the mirror image of the question above is also pertinent: how are developers constituted as a group? The upshot of this is, and again a pressing issue illustrated by Grundin, how are the relations between developers and users to be controlled?

\subsection{A Theoretic Issue}

Woolgar $(1991,1994)$, as a consequence of spending a period as a project manager assistant in a microcomputer manufacturer, argued that the user is a social construction - the product of processes of delineation and definition. Woolgar proposes that preconceptions about users are more than just an interaction in a process of requirements definition; they are deeply held and "engrained in company culture" (Woolgar 1994, p. 213). As discussed above, it appears that this theoretic position accords with descriptions of what problems developers have faced in seeking user participation. However, Woolgar's report was restricted to the development of a piece of hardware for a potential market of users. In this instance it is plausible to argue that the user is configured through preconceptions of what users are and that users' actions will then be prescribed through having to follow instructions as to how to use the artefact so that the computer will work. This is obvious because, at the outset, for a new product no users exist as such. The question is whether we can extend this analogy of user as construct to other contexts of computer development. The answer is probably yes, although the means by which users are configured may be somewhat different.

One of the issues for those developing systems and seeking users is to find users who are representative of users in general. This is not only a problem for those developing generic software products, as shown by Grundin, but is shared by those developing systems for individual organizations or within organizations (contracted or in-house development). For the former the problem is, who represents the user? Is it definitely not the managers or information systems specialists but rather the computer users themselves, as Grundin supposes?

Even in projects developed within organizations, a similar issue arises: who will be users and how are they to be represented? The reasons why this is important are twofold. First, those developing systems seek a single source of requirements specification, as is suggested above, and second, those producing that requirements specification are expected to become more knowledgeable of designer concerns and develop requirements specifications accordingly. One of the ways to do this is to use techniques that involve users in development. Any involvement of users by definition makes visible parts of the social and brings them into a relationship with development. It is this participation of users that is constitutive of users. Users are not users until 
they are involved in development in some form. Requirements techniques organize so as to create users that will enable representation of the organization qua social.

How these techniques are designed and used are of importance to developers. If communication between users and developers is unregulated, then dangers are recognized of developers being side-tracked by unrepresentative user demands or users being put off by developers. The development of inscriptions to represent users' requirements is an important step in the process of control and one that is closely linked to the constitution of users. The capabilities of the inscriptions that are generated in terms of their mobility, immutability and combinability are important for developers because it is only when combinations of all three are present that they are capable of producing networks of stable relations among designers and also between designers and users. This brings us to the second point: developers are also constituted in this process. As Grundin has observed, who the designers are and how they are to be organized are important issues; ones that have been recognized since the late 1960s. Producing networks of relations that become teams of designers is due, in no small measure, to the circulation of inscriptions of requirements that have been made mobile, combinable and immutable. Put in this way, the importance of techniques and the inscriptions they generate in constituting users, developers and their interrelations, is hard to underestimate.

Finally, a consequence of focusing on users and designers is to present them as representative of the social and the technical respectively. What we find is the search for the end user as representative of the social and a focus on the developer, and in particular, the programmer as representative of the technical. Within this relationship, all others tend to be relegated to obstacles to communication between the two or to the clutter of nonuser components (Curtis, Krasner and Iscoe 1988; Grundin, 1991).

To assist in the analysis, two variations of relations between users as representing the social and developers as representing the technical are identified (see Figure 3 ). The first is termed user participation and the second dialogue with users. Both formulations share a presumption that users should/do speak for the organization qua social; however, a distinction may be may made as to how users and designers are seen as interacting. In the former, users are central and are actively engaged in processes/techniques that produce an inscription of the social. Developers are those who seek to align the information technology to that inscription, either by the provision of technical alternatives, as in the case of ETHICS (Mumford 1983), or in unproblematically incorporating the inscription into the technical as in Soft Systems Methodology (Checkland and Scholes 1990). In the category of dialogue with users, the expectation is that users and designers will work together in the production of requirements but that this process should entail techniques that produce inscriptions. This latter category is perhaps the most ambitious and comprises approaches such as the cooperative approach originating in Scandinavia and others proposing an emancipatory approach to systems development (Greenbaum and Kyng 1991; Hirschheim and Klein 1994; Murray and Willmott 1991). 


\begin{tabular}{|ll|}
\hline $\begin{array}{l}\text { Users speak for the social } \\
\text { using requirements specifications }\end{array}$ & $\begin{array}{l}\text { Users speak for the social through } \\
\text { dialogue and games }\end{array}$ \\
$\begin{array}{l}\text { Fitting the technical and the social } \\
\text { together }\end{array}$ & Aligning the technical to the social \\
$\begin{array}{l}\text { Requirements as a product of the } \\
\text { requirements process }\end{array}$ & Requirements as a process \\
Techniques of user participation & Techniques of dialogue with users \\
\hline
\end{tabular}

Figure 3 Classifying Approaches to User Involvement in Requirements Analysis.

\section{USER INVOLVEMENT: QUICKethics/ETHICS}

Those approaches classified as user involvement approaches to the issue of requirements produce inscriptions for designers. Users are seen as important in speaking for the organization both in providing information about the organization and in participating in processes that may lead to a redefinition of the organization. The result of these processes is the production of an inscription (a requirements specification) that represents the organization and which may then be used by designers as representatives of the technical. The processes of user involvement are also processes engaged in the constitution of users so that they are seen as able to speak for the social. To do this, those in the organization have to be accepted as representatives of the social and seen as users. Second, users have to be organized so that they speak in terms that can be mobilized. In other words, they must be able to formulate their observations in a manner that is capable of translation into a representation which is immutable and mobile. Similarly, users must be organized so that they can read these inscriptions and comment on them. Finally, the outcome of these processes is an inscription that is, dependent on the context, immutable, mobile and combinable; it represents the organization and may then be used by developers who are seen both to represent information technology and to work in relation to the requirements produced by the processes of user involvement (see Figure 2). The requirements produced by these approaches are seen to be fixed for the medium term. In some approaches, such as ETHICS/QUICKethics, users speak for the organization, designers for information technology and the objective is to align them. In other approaches, such as soft systems methodology, the technical is to be aligned with the representation of the social produced by the methodology. The approach that will be examined in detail here is ETHICS/QUICKethics.

The ETHICS methodology was developed by Mumford in the late 1970s. It has become well known as a methodology of systems development that advocates user 
participation and, arguably, it is the best known methodology of user involvement in the information systems literature (Episkopou and Wood-Harper 1986; Ehn 1988; Flynn 1992; Hirschheim and Klein 1989, 1992, 1994; Jirotka and Groguen 1994; Mumford 1983, 1985, 1987, 1993, 1995; Mumford and Henshall 1983; Mumford and MacDonald 1990). It is because of the status of ETHICS as an exemplar of a methodology of user involvement that it is important to examine it in some detail.

Mumford's socio-technical approach has become influential but it is not without critics. The criticisms leveled at her approach can be split into two groups. First, it is argued that this approach neglects "asymmetrical relations of power" and assumes that the problem is one of communication between designers and users (Hirschheim and Klein 1992; Willmott et al. 1990). As Willmott et al. (p. 258) put it, this approach ignores "the understanding that meaningful dialogue and participation may be impeded or distorted by unfavorable material and ideological conditions." Others disagree with this appraisal: both Mumford herself (Mumford 1994) and Hirschheim and Klein (1994, p. 93), in a change of heart compared with their earlier analysis (Hirschheim and Klein 1992), propose that ETHICS "strives to realize the so-called 'ideal speech situation'." Second, ETHICS and, for that matter, soft systems methodology, have been criticized for placing " $a$ priori classifications and categorizations of human behavior" on what is occurring in organizations and giving little guidance to analysts (Luff, Heath and Greatbatch 1994, p. 285). ${ }^{2}$ Disagreeing with Luff, Heath and Greatbatch and contrary to their argument, the representation/classification capacities of ETHICS and also soft systems methodology are some of their greatest strengths for managing a process of requirements analysis through their capacity to provide agreed inscriptions of the organization, although it is likely that the representations furnished by ETHICS/QUICKethics will not accord with the analysis of video or ethnography.

Mumford (1985, p. 97) introduces the rationale for ETHICS as follows:

It can be argued that the most important stage in systems design is the definition of systems requirements....It is essential for both the technical designers and the users of the new system to be absolutely clear on what they want the system to achieve. Only if systems requirements are clearly defined will the technical specialists have a set of required outputs against which they can match existing hardware and software. Similarly, only if systems requirements are clearly defined will users have a set of precise expectations of what they want the new system to help them achieve. These expectations should be specified as a set of objectives directed at improving personal and group efficiency, effectiveness, job satisfaction and the quality of working life. They will be attained through associating

${ }^{2}$ In other words, they ignore how activities are carried out in the workplace and rely instead on the accounts of those working there (see Jirotka and Groguen 1994, p. 6). 
new technology with new organizational structures and using both of these as a means of achieving these objectives.

This quotation shows some of the moves that are seen as important in ETHICS. First, the issue of requirements is positioned as between technical designers on the one hand and users on the other. The role of each is to produce clear definitions of what is required. Users speak for the social by furnishing designers with a set of "required outputs" while designers speak for the technical by assessing and matching the options of hardware and software. For the designers to speak effectively, they must have a defined set of requirements that represent the social. ETHICS provides mechanisms for users and, to a lesser extent, developers, to make visible what is social and what is technical. The social "should be specified" as objectives to be achieved in certain categories. ETHICS then provides instruments to measure (make visible) and evaluate (represent) the social in specific formulations. For example, job satisfaction is measured using a questionnaire. The supposition of ETHICS is that the technical and social constitute different domains, each of which needs to be associated, and that this may be accomplished through mechanisms employed by designers and users alike. As Mumford remarks,

This design strategy can only be used if systems designers have a clear and comprehensive knowledge of the needs and behaviour of the user department. The involvement of users in the design process is seen by the author as the most effective way of achieving this knowledge. ETHICS facilitates such participation by providing a simple step-by-step method that can be used by non-technical staff to identify their efficiency, effectiveness and job satisfaction needs and problems. [Mumford 1985, p. 99]

This analysis of ETHICS/QUICKethics will focus on two issues: first, the means by which users are constituted and come to speak for the social; second, how designers are constituted and come to speak for the technical.

More recently, Mumford has produced a variant of ETHICS known as QUICKethics, which is described as "the front end of ETHICS" and is specifically designed for requirements analysis (Mumford 1995, p. 79). QUICKethics is portrayed as being able to assist in the following processes:

- Analyzing roles and responsibilities prior to considering information needs.

- Identifying and prioritizing information needs.

- Creating and applying a core information system as a preliminary to building or improving a larger one.

There is some confusion as to who should use QUICKethics; in some cases, Mumford (1995, p. 52) proposes that QUICKethics is used "to assist managers to define their information needs prior to the introduction of a management information system" (emphasis added), whereas, in other places, QUICKethics is seen as enabling the future users of a new system, or their representatives, if users form a large group, to work individually and as a group, thinking through 
their roles and responsibilities and relating these to their information needs. [Mumford 1995, p. 95] ${ }^{3}$

Almost in the next sentence, Mumford uses the term manager again. From this, it is clear that there is considerable ambiguity as to the relationship between managers and users and whether these two terms are interchangeable in QUICKethics. This issue goes to the heart of the criticisms raised above that Mumford fails to recognize power inequalities in the workplace. It is not that she does not recognize a concept of power but that she considers that the use of ETHICS is capable of ameliorating the situation (see Mumford 1995, pp. 55-62). ${ }^{4}$ This is a rather Panglossian perspective. Although criticism is probably justified, it neglects the role of techniques in providing a representation of the social and it is this ability to organize an agreed representation of the social that is important for information systems development, be it from the perspective of a users or a managers.

The selection of users is not given much attention in QUICKethics; they are assumed unproblematically as either future users or representatives of future users. ${ }^{5}$ Arguably, someone has to define who are future users and, in doing so, they exercise judgment as to what the bounds of the social are in a particular instance. This judgment is based on assumptions of how the social will be affected by the technical or, in other words, the constitution of the social is set by its expected relation with the technical. This judgement must be exercised regardless of whether managers or others or both are assumed as users. Although the social is taken as being comprised of users, it is the ability to describe the characteristics of users that is important in QUICKethics. Let us now look at ways in which QUICKethics defines users.

Mumford (1995, p. 94) argues that one of the problems of more traditional approaches to requirements analysis that use interviewing techniques is that "[it] has the major disadvantage of leaving the systems analyst with the task of integrating a number of different sets of needs."6

${ }^{3}$ As an example of QUICKethics, Mumford (1995) describes nurses creating the requirements for a new nursing information system.

${ }^{4}$ Mumford discusses approaches to participation and "work humanization" by Follett, Handy and the human relations school. She argues that ETHICS strives to reach a situation where "there is no place for regulation or coercion; everything should emerge from discussion and agreement' (p. 55), although she admits that it is only a "small step in the right direction" (p. 62).

${ }^{5}$ Elsewhere, in a discussion of participation, Mumford (1995, p. 20) suggests that "if consensus or representative design is used then, ideally, the design group should be democratically elected." This did not occur in the example of QUICKethics given in this text and this is considered to be a serious omission.

${ }^{6}$ Mumford ignores the claim of modeling techniques such as data flow diagrams, entity relationship diagrams or object oriented techniques in enabling different "sets of needs" to be compared and made coherent. 
She considers that requirements analysis has to be a social process based on group discussion that "enables users to understand better the roles, responsibilities, problems and information needs of their colleagues" (p. 95). However, these roles, responsibilities, problems and information needs are not just elicited through discussion; QUICKethics provides activities to produce them. The primary means is a questionnaire that asks the manager/user to

describe his or her work mission, key tasks, critical success factors and major problems. These are seen as essential elements of the managers' job. They are also almost certainly the most stable. They will only change if the manager experiences major changes of role and function.

QUICKethics then continues by an analysis of each key task based on the cybernetic model of a viable system developed by Beer (1981). This model represents the organization as comprising of five levels and it "assists the manager to examine systematically their roles and responsibilities" (p. 96). The questionnaire then

asks each manager to use this job analysis to identify his or her information needs; to separate these into "quantitative" and "qualitative" needs, and to prioritize them into "essential," "highly desirable," and "useful."

[Beer 1981, p. 96]

After completing the questionnaire, the managers/users meet for a two day session in which they discuss their mission, key tasks, critical success factors and principal problems and describe their essential information needs. Each manager/user's essential information needs are written up and "gradually, a picture of the group's essential needs is built up until agreement is reached that a viable core information structure has been achieved" (Beer 1981, p. 97).

Mumford argues that QUICKethics gives empowerment to users and allows both their knowledge to be used and their interests to be respected in the development of a new system. QUICKethics, Mumford suggests, enables organizations to learn how to learn by not only solving problems but through reducing or removing the factors that may have caused these problems in the first instance.

What QUICKethics provides are techniques which those who use QUICKethics, and thus potential users, engage in. Participants have to represent their work in relation to a work mission that comprises key tasks. Each key task has objectives, requires daily activities and needs information. In turn, a key task has critical success factors and problem areas, both of which require information. Finally, a key task has targets which also require information. QUICKethics is representing the work of users in a formulation that is seen as natural and systematic. It may appear that the QUICKethics questionnaire is no more than a systematic appraisal of people's work. However, it engages people to reformulate/translate their working experiences into answers that indicate the presence of these features. For example, the assumption is that everyone has a key mission and that, at worst, the problem is the articulation of an implicit key mission. It is assumed that such a mission must be comprised of identifiable tasks that in turn may be subdivided into daily activities. In other words, the questionnaire respondent, if the respondent is to engage in QUICKethics, is being 
configured into someone that is represented as working on a rational and systematic basis.

If engagement in completing the questionnaire in terms of these categories is a first translation, a second, and related, move is to cast each task, daily activity, problem, target, and critical success factor as being conditioned primarily on the presence or absence of requisite information. For example, a critical success factor may only be met if certain information is available. This configures the participant as engaged in systematic and rational work processes which necessitate the participant to be a user of information. Once this move has been made, then the role of participants is to create a list of essential information which is needed for their key tasks. As a consequence, the participant in QUICKethics becomes configured as a rational user of information to perform activities that are systematically related.

These users are taken as those who should speak for their activities on grounds of empowerment, participation and democracy. In other words, no one else has the ability to say what these users do but, on the other hand, the representations the social has been translated into enable a coherent picture of the organization to be created on the basis of information. In terms of inscriptions, the first move is to engage those in the workplace in the translation of their work into the vocabulary of cybernetics and a second is to represent these in terms of information needs. Once this has been done, an inscription can be produced which lists common information requirements. Such an inscription is, dependent on the context, a combinable immutable mobile and capable of both representing users and being used by developers. This process resolves the problem Mumford discusses of leaving the systems analyst with the task of integrating a number of different sets of needs. User participation has done this already. Users are configured in their engagement in QUICKethics and are seen as speaking for the social but the social as represented in the vocabulary of QUICKethics/cybernetics. However, once users have produced their information requirements, the users in turn may be represented by this inscription. At this point, the social is being related to the technical by the information it requires, a situation little different than orthodox requirements techniques, the differences being that the process by which that point has been reached and, secondly, the role assigned to developers.

This process, by which users come to be seen as representing the social, is dependent on the process of QUICKethics being seen as legitimate and useful. Hence the importance placed by Mumford in describing the utility of QUICKethics not only on democratic grounds but also on efficiency gains. If the utility of QUICKethics is questioned, then the status of the inscriptions that it produces may not be accepted as representative by others. For example, developers may wish to use analytic techniques such as data flow diagrams to represent the social mindful of Ackoff's warning against users defining their own information needs.

What of the designers and their place in QUICKethics? The process of QUICKethics and the inscriptions it produces are clearly designed in relation to a conception of the technical as capable of automating the social and thus being able to make the 
social more efficient. On the other hand, designers are not involved in the production of the representation of the social which is left as the domain of users. ${ }^{7}$ The deployment of a computer system is seen as either being developed within the organization or though the purchase of a software package. In either case, the domain of the technical is seen as being represented by technical experts/developers who are able to talk about technology (Mumford 1995, p. 43). However, the role assigned to technology is twofold. First, it is seen as a factor as in the following quotation: "Technology is, of course, [a]... actor that can reduce or increase freedom" (Mumford 1995, p. 60). Second, technology is seen as supplementary to the social and it should be applied once the social has been reorganized: "Ideally, if work is to be fundamentally reorganized this should be done before the technical system is selected" (Mumford 1995, p. 43). ${ }^{8}$ In short, QUICKethics does not dwell on the technical, leaving it as something that will be capable of delivering the information needs of users though the work of developers.

To conclude, the techniques and representational practices of QUICKethics in particular configure the user as representing the social in a vocabulary that enables immutable and mobile inscriptions to be produced. Of course, the characteristics of the inscriptions depend on the context in which they are deployed. Technology is left as a domain to be represented by developers and to be related to through the clear articulation of information requirements.

\section{DIALOGUE WITH USERS: THE COOPERATIVE APPROACH}

Approaches classified here as advocating dialogue with users share several characteristics. First, the presumption that the technical should be developed in relation to the social and not vice versa. Second, that those working within the social speak for the social. Third, that the process of requirements analysis is in itself misleading. Requirements are not seen as having a status that enables them to be captured and defined; rather it is more appropriate to consider requirements analysis as integral in a process of design of computing artefacts. Finally, it is taken as given that the way to create information systems is to have users as full partners in design (Greenbaum team.

${ }^{7}$ In ETHICS, the situation is more complex as designers and users may interact on a design

${ }^{8}$ This view of technology sits uneasily with Mumford's assertion that "everything that BPR (business process reengineering) offers is to be found in socio-technical design" (1995, p. 48). What ETHICS/QUICKethics does not acknowledge is a capacity for technology to transform organizations. The chameleon nature of ETHICS/QUICKethics is more apparent when elsewhere Mumford argues that this approach follows Habermas's dictums on the creation of communicative competence (Mumford 1994). 
and Kyng 1991, p. ix). These assumptions differentiate them from the approaches termed here as user involvement in two respects. User involvement approaches, as their name suggests, involve users in the process of requirements production but they differ from dialogue with users' approaches in, first, assuming that a fixed set of requirements may be produced and, second, in presuming that the relationship between designers and users will be through the product of this process. In design by doing, there is an expectation that designers and users work together as equal partners in systems development and that requirements are integral to situated design and cannot simply be decontextualized into formal inscriptions.

The approaches classified here as dialogue with users are commonly known as either the cooperative design approach or as approaches to participative design (PD) (see ACM 1993; Greenbaum and Kyng 1991). Most of this work originated in Europe and has been associated with IFIP Working Group 9.1 on Computers and Work (see Clement and van den Besselaar 1993). More recently, there has been increasing interest in participative design in the United States (ACM 1993). Probably the best known influence on the development of these approaches has been work done in Scandinavia which has been reported in several books (Bjerknes, Kyng and Ehn 1987; Ehn 1988; Greenbaum and Kyng 1991). However, it has proved difficult to classify the Scandinavian approach within the information systems literature. On the one hand, Hirschheim and Klein (1992, pp. 325-326) describe them as complex and "not having transformed themselves into methodologies" and they propose that the approach itself has changed from a "radical structuralist" toward a more "neohumanist" paradigmatic affiliation while also changing name from the "collective resource" approach to one of "cooperative design." On the other hand, the very lack of cohesiveness of the cooperative design approach enables classifications to be developed that simply split it into a series of techniques that may be deployed as needed by systems developers (see Muller, Wildman and White 1993). Given this interpretative flexibility, the analysis is restricted to two well known sources: first, the book Design at Work that was produced, in part, to highlight key ideas in Scandinavian (and American) design (Greenbaum and Kyng 1991, p. ix) and, second, the experiences of the UTOPIA project ${ }^{9}$ which is "probably the best known PD [participatory design] project" (Clement and van den Besselaar 1993, p. 30).

${ }^{9}$ The aim of the UTOPIA project was to build computer based tools and develop other skills for graphics workers in Nordic countries. It ran from 1981 to 1985 as a collaboration between graphic workers, computer and social researchers working with Scandinavian graphics work unions and funded by a variety of mainly government and academic sources (see Bødker et al. 1987; Ehn 1988, pp. 327-348). One objective was to produce a marketable technology for graphic design. This failed due to "a lack of technical competence within the company responsible for developing and marketing the software product" and "opposition from both management and the union of journalists" (Clement and van den Besselaar 1993, p. 34). 
What interests us here are issues of the constitution of designers and users in the techniques of this approach. This is of special relevance given the importance attached to users as full partners in design.

Users, in this approach, are seen as

not as one homogeneous group, but, rather, as diverse groups of people who have competence in work practices. Our perspective focuses explicitly on all the different groups of people using computers in their work, and not on the managers. [Greenbaum and Kyng 1991, p. 3]

This perspective on users is premised on the belief that work is fundamentally social and that work practice is comprised of situated actions. This means that workplace life is "not easily describable" (Greenbaum and Kyng 1991, p. 4) and that new techniques are needed to "capture this complexity, and to develop a more detailed understanding of its depth."

The way in which this complexity is to be understood is fourfold: mutual learning between users and designers about their respective fields, use of tools in design which are familiar to users, envisionment of future work situations so that users can experience emerging designs, and basing the design process in the practice of users. As Greenbaum and Kyng put it, cooperative design is

an attempt to look at the development of computer systems as a process, where people as living acting beings, are put back into the center of the picture. A picture of the workplace, where the situations that people find themselves in, with all its conflict-laden social and political tensions, comes under close scrutiny.

The outcome of this is the observation that no method or universally applicable set of tools are available, rather that cooperative design depends on the situations in which it is applied.

What of designers? Greenbaum and Kyng (p. 20) propose to "refer to the technical people as designers in order to keep our eyes on the process of developing computer systems." Designers include the gamut of systems analysts, programmers, consultants, and systems engineers. In other words, their common characteristic is that they may speak for the technical. However, the cooperative approach views technology differently than other approaches. The assumption is that technology is a tool: "Computer systems are tools, and need to be designed to be under the control of the people using them."

Having introduced the conceptions of user, designer and technology in this approach, we proceed to describe some of the techniques used in design. Two of the more important in the UTOPIA project were the use of mock-up simulations of computer artefacts for users (design by doing) and, second, the use of an organizational design game to support discussions of existing and future work (design by playing) (Ehn and Kyng 1991; Ehn and Sjögren 1991).

Ehn and Kyng describe how they used cardboard models of printers and computers with drawings taking the place of the screen. They argue that users could not understand the descriptions given them using orthodox techniques. What they found is that 
if cardboard models of a possible system were produced, users could actively use them and the cardboard models were understandable, fun and cheap to produce. Ehn and Kyng argue that they were very successful in enabling users to envision what could be done; however, problems arose when users realized that a completed system would take some time to create. As Bødker et al. (1987, p. 257) remark, "the graphics workers who were used to rapid concrete results in their daily work, found that work progressed too slowly and was too abstract."

A second technique, called the Organizational Kit, was a game based on the traditional production flow in a newspaper and the artefacts and functions that were needed. Each item, artefact and function was represented by cards of different colours and shapes. The designers introduced the users to this game having first observed what the users did. The game was based around production at two newspapers, both computer based but with different work organizations. Ehn and Sjögren found that the game was a means to "create a common language, to discuss the existing reality, to investigate future visions, and to make requirements specifications on aspects of work organization, technology and education" (p. 252). They argue that social interaction came into focus using the game and that "existing hardware and software" were "more or less taken for granted" (p. 254). This, they suggest, shows that the basic problem is one of organizational change and not technology.

These brief descriptions of two techniques used in the UTOPIA project pose interesting issues in relation to conceptions of users, designers and the relationship between the technical and the social. First, techniques such as the Organizational Kit are produced by designers and played by designers and users. Both learn from this game but the rules of the game have been set up by the designers. So though users may speak for the social, they do so within the vocabulary constructed by developers. This game does not address the technical, which is taken as given, but it is probably open to designers to speak for the technical and open up possibilities for users if they so desire. Second, the choice of users is of importance. In part, this reiterates points made in relation to QUICKethics; the difference here is that the subsequent history of UTOPIA shows that both management and journalists refused to implement the proposed UTOPIA system. Managers had deliberately not been seen as users while journalists could be users but were not involved in the design. The upshot is that the users chosen to design the system were not contiguous with the users that were designed into the resulting system and, perhaps as a consequence, those not involved did not accept the new system. Put differently, UTOPIA techniques assisted in constructing a role of users not just through the creation of a UTOPIA artefact but also through techniques such as the Organizational Kit, which creates roles for those who act as player/designers, and subsequent design then produces a variety of other users who must interact with the new system if it is to work.

Third, some of the problems encountered above may be linked to the conception of technology as a tool. The tool metaphor emphases the relationship between tool and user in which the user is shaped by and may shape the tool as in the use of cardboard prototypes. However, this metaphor obscures characteristics that are often 
ascribed to the technical, such as the ability to make visible work processes and the capability to combine and mobilize that information. In other words, the designers' metaphor to enable the shaping of the technical through cardboard prototypes did not adequately represent characteristics of the technical.

So, we find a situation where, on the one hand, users were chosen and through techniques developed a vocabulary to describe the social but were unable to represent the social as subsequent problems with management and journalists imply. On the other hand, designers seek to represent the technical through techniques such as cardboard prototypes but are also unable to do so successfully. Their lack of success is shown by the inadequacy of the tool metaphor, by their inability to produce the actual technical artefact quickly and, finally, by the failure of the hardware/software manufacturer to produce a finished product.

It has been suggested here that designers were able to speak, if ultimately unsuccessfully, for the technical and that they are intimately involved in producing the vocabularies and techniques for describing the social. This ability leads to designers, as Ehn and Kyng (p. 194) put it, "as referees of the game: the gods that make the other players obey the given rules."

Not only are designers placed in this relation to those working in organizations and constituted as users but the characterization of designers is opaque. They are, it appears, a homogeneous group of people committed to doing the best for the users in the context of that project. Although this is laudable, it conceals any relationships between different designers; for example, who gets to speak to users and who codes the system? Perhaps this role taken on by developers is characteristic of the project based work where it derives, but its naiveté is striking and somewhat disquieting when we consider the concerns raised by Grundin and others discussed earlier on the heterogeneity of developers, the difficulties in managing the interaction between developers and users, and the demands on developers to be effective and efficient.

In summary, although it is difficult to characterize the cooperative approach which is avowedly nonmethodological, we may still draw some conclusions. First, although users speak for the social, we find that designers use techniques to develop vocabularies to describe the social for users. A problem arises in users being representative of the social because of what appears to be the conflictual and situated nature of the relations within it. Second, designers have created techniques that enable users to shape the technical as tool-like. Although designers speak for the technical, the composition of designers remains problematic as is their ability to speak for the production of technical artefacts. Finally, the characterization of the relations between the social and the technical as one as communication between users and designers is problematic. The source of difficulty does not appear to lie in what are unfavorable material and ideological conditions because it appears possible within the confines of these projects for resources to be available. Rather, it resides in the conflation of users as representing the social and designers as representing the technical. Each grouping may be able to interact successfully using a shared vocabulary, but it appears far more difficult for either grouping to continue to speak for either the social or the technical over longer periods of time as the experience of UTOPIA bears out. 


\section{DISCUSSION AND CONCLUSIONS}

The argument presented here seeks to show how the categories of user and designer (let alone organization and information technology) are constituted by the techniques that seek to represent them. In other words, there are links between the organization of representation (requirements techniques) and the representation of the organization (requirements). This may appear to be an obvious comment, but drawing attention to it throws into stark relief some of the difficulties for those developing or using requirements techniques. As was found in science, representation is a form of intervention and what needs to be recognized is the extent of this intervention in any particular context. It is not that we can wish away the difficulty users may have in articulating their requirements but we need to recognize the extent to which the techniques that are used provide the vocabularies for them. This is a form of intervention that is subtle and far reaching and the translation that it entails may be extensive.

For those interested in research into systems development, the trajectory of developing yet better methodologies to resolve the problems of systems development has run its course. Ontological and epistemological analyses remain both difficult to apply in relation to methodologies and are, at base, philosophical. Indeed putting trust in methodology alone as a means of ensuring success in development is an act of faith that is unwarranted (cf. Hirschheim and Klein 1992). Not only are there a series of moves being made in the very constitution of these techniques - some of which this paper has attempted to illuminate - but we find that when it comes to requirements analysis in practice, methodologies are used as a resource and applied with considerable flexibility (see Westrup 1996).

Despite the arguments raised in this paper, user participation in systems development is both desirable and useful. Some of the difficulties that need to be addressed when user participation is invoked in systems development have been presented. Hopefully, the outcome will be that a more considered and indeed beneficial experience of user participation may be engendered. Four points arise from this analysis.

First, a recognition that user participation is engaging in a political process in which certain questions become central: who represents who; how are others to be convinced that this representation is legitimate; and how is that representation to be constituted? Using techniques of user involvement may help in addressing these issues but equally, and depressingly perhaps, more frequently the deployment of techniques displaces these questions and puts others in their place. For example, QUICKethics treats the issue of power relations in a naive (as empowerment) and often contradictory way (sometimes as emancipatory at other times like business process reengineering). This well known example of user participation does not do justice to the important issues of representation that its deployment raises.

Second, it is important to realize that users are constituted by the process of engagement in systems development. There is no pristine user awaiting the developer, and the particularity of any requirements analysis technique (as well as its deployment) will inevitably shape the types of user participation that occur. One of the prime difficulties is that once users are constituted as a group they are often 
unable to speak because they possess no legitimate vocabulary (in terms of systems development) that may be inscribed. Two moves have to be made: first, users have to acquire some representation of the technical and, second, they have to articulate their experience and understanding of the social in terms that may be inscribed. The latter is potentially extremely precarious as users frequently have to rely on others' (systems developers' or facilitators') vocabularies of the social in order that their experiences may be inscribed. For example, QUICKethics structures users' inscriptions of the social as a cybernetic system, while even in Scandinavian approaches to cooperative development we find that users have to gain insights into their work through the use of games created by developers.

Third, the limitations of users' ability to speak for the social qua organization needs to be recognized. It cannot be assumed, although it frequently is, that a homogeneous inscription of the social is going to be more than a construct of the development process. For instance, when detailed engagement with users has occurred in the cooperative approach we find that all aspects of the social just cannot be included. Those who are left out, be they managers, other elements of the workforce, or perhaps forces outside the organization, may act to compromise the users' claims to represent the social, especially as time elapses after the creation of the initial requirements. The experience of the UTOPIA project is a good example of this: the claims of the users to represent the social was shown to be deficient as both management and journalists failed to support the project. More wide-scale difficulties are often apparent when reviews of user participation projects are undertaken (see Clement and van den Besselaar 1993).

Fourth, users need to be wary of how the technical is represented to them and realize that any one metaphor or representation is at best limited and, at worst, misleading. Seeing a system being demonstrated should not lead to accepting its adequacy. As a representation of the technical, demonstrations are more akin to a theatrical performance whereas every eventual system in a working environment may perform in a very different way.

This paper has used a theoretic approach viewing the early stages of systems development as a process of representing organizations by having users speaking for them and technology by having developers as spokepersons. It attempted to show how these are practical difficulties in systems development not just theoretic issues and went on to show, in some detail, how requirements analysis techniques of user involvement attempt to resolve these problems. To aid the analysis, two types of user involvement were identified: user participation centered on the creation of requirements specifications (inscriptions) and dialogue with users which stresses far reaching communication between developers and users. In both categories, it was shown that the ambitions of user involvement are compromised by techniques which have to constitute users (and developers) while attempting to foster involvement.

What of the role of qualitative research? A consequence of this paper is that, in qualitative research, attention needs to paid to three issues. First, we must recognize that the vocabularies of research are problematic; terms such as users and developers have been constituted through a variety of processes of which requirements analysis techniques are one of the most important. Naive description of "what is there" is not 
an option in future qualitative research. Second, constructive critique of qualitative approaches is necessary and important. For example, although the active engagement of researchers in IS development is admirable, both theoretic difficulties and shortcomings in practice need to be identified and analyzed (see Westrup 1996). Finally, qualitative research needs to look carefully at the very concepts of technology and organization that are so frequently invoked. If, as has been argued, they are constituted and not unchanging, then many of the well known classifications in qualitative research into IS development will need fundamental rethinking (for example, Hirschheim, Klein and Lyytinen 1996).

\section{ACKNOWLEDGMENTS}

I would like to thank Brian Bloomfield, Geoff Walsham, and Hugh Wilmott for comments on a previous incarnation of this paper.

\section{REFERENCES}

ACM (1993). Special issue on "Participative Design." Communications of the ACM, Volume 36, Number 4.

Beer, S. (1981). The Brain of the Firm. Chichester, England: Wiley.

Bjerknes, G.; Kyng, M.; and Ehn, P. (1987). Computers and Democracy. Aldershot, England: Avebury.

Bødker, S.; Ehn, P.; Kyng, M.; Kammersgaard, J.; and Sundblad, Y. (1987). "A Utopian Experience: On Design of Powerful Computer-Based Tools for Skilled Graphic Workers." In G. Bjerknes, P. Ehn, and M. Kyng (Editors), Computers and Democracy. Aldershot, England: Avebury, pp. 251-278.

Carmel, E., Whitaker, R., George, J. (1993). "PD and Joint Application Design: A Transatlantic Comparison." Communications of the ACM, Volume 36, Number 4, pp. 40-48.

Checkland, P., and Scholes, J. (1990). Soft Systems Methodology in Action. Chichester, England: Wiley.

Clement, A., and van den Besselaar, P. (1993). "A Retrospective Look at PD Projects." Communications of the ACM, Volume 36, Number 4, pp. 29-37.

Curtis, B.; Krasner, H.; and Iscoe, N. (1988). "A Field Study of the Software Design Process for Large Systems." Communications of the ACM, Volume 31, Number 11, pp. 1268-1286.

Ehn, P. (1988). Work-Oriented Design of Computer Artefacts. Stockholm: Arbetslivscentrum.

Ehn, P., and Kyng, M. (1991). "Cardboard Computers: Mocking-It-Up of Hands-onthe-Future." In J. Greenbaum and M. Kyng (Editors), Design at Work: Cooperative Design of Computer Systems. London: Erlbaum, pp. 169-195. 
Ehn, P., and Sjögren, D. (1991). "From System Descriptions to Scripts for Action." In J. Greenbaum and M. Kyng (Editors), Design at Work: Cooperative Design of Computer Systems. London: Erlbaum, pp. 241- 268.

Episkopou, D., and Wood-Harper, A. (1986). "Toward a Framework to Chose Appropriate IS Approaches." The Computer Journal, Volume 29, Number 3, pp. 222-228.

Flynn, D. (1992). Information Systems Requirements: Determination and Analysis. London: McGraw-Hill.

Greenbaum, J., and Kyng, M. (Editors) (1991). Design at Work: Co-operative Design of Computer Systems. London: Lawrence Erlbaum Associates.

Grundin, J. (1991). "Obstacles to User Involvement in Software Product Development, with Implications for CSCW." International Journal of Man-Machine Studies, Volume 34, pp. 435-452.

Hirschheim, R., and Klein, H. (1989). "Four Paradigms of Information Systems Development." Communications of the ACM, Volume 32, Number 10, pp. 11991216.

Hirschheim, R., and Klein, H. (1992). "Paradigmatic Influence on IS Development Methodology: Evolution and Conceptual Advances." In M. Yovits (Editor), Advances in Computers, Volume 34, pp. 294-392.

Hirschheim, R., and Klein, H. (1994). "Realizing Emancipatory Principles in Information Systems Development: The Case of ETHICS." MIS Quarterly, Volume 18, No., 1, pp. 83-109.

Hirschheim, R.; Klein, H.; and Lyytinen, K. (1996). "Exploring the Intellectual Structures of Information Systems Development: A Social Action Theoretic Analysis." Accounting, Management and Information Technology, Volume 6, Number 1/2, pp. 1-64.

Jirotka, M., and Groguen, J. (Editors) (1994). Requirements Engineering: Social and Technical Issues. London: Academic Press.

Latour, B. (1987). Science in Action. Milton Keynes, England: Open University Press.

Lei, Lei (1994). User Participation and the Success of Information Systems Development: An Integrated Model of User-Specialist Relationships. Ph.D. Dissertation, Tinbergen Institute Research Series, Number 73, Amsterdam: Thesis.

Luff, P.; Heath, C.; and Greatbatch, D. (1994). "Work, Interaction and Technology: The Naturalisitic Analysis of Human Conduct and Requirements Analysis." In M. Jirotka and J. Groguen (Editors), Requirements Engineering: Social and Technical Issues. London: Academic Press, pp. 259-288.

Muller, M.; Wildman, D.; and White, E. (1993). "Taxonomy of PD Practices: A Brief Practitioner's Guide." Communications of the ACM, Volume 36, Number 4, pp. 26-27.

Mumford, E. (1983). Designing Human Systems for New Technology: The ETHICS Method. Manchester, England: Manchester Business School.

Mumford, E. (1985). "Defining System Requirements to Meet Business Needs: A Case Study Example." The Computer Journal, Volume 28, Number 2, pp. 97-104. 
Mumford, E. (1987). "Sociotechnical Systems Design: Evolving Theory and Practice." In G. Bjerknes, P. Ehn and M. Kyng (Editors), Computers and Democracy Aldershot, England: Avebury.

Mumford, E. (1993). "The ETHICS Approach." Communications of the ACM, Volume 36, Number 4, p. 82.

Mumford, E. (1994). "Technology, Communication and Freedom: Is There a Relationship?" In R. Baskerville, S. Smithson, O. Ngwenyama, and J. DeGross (Editors), Transforming Organizations with Information Technology. Amsterdam: North Holland, pp. 303-322.

Mumford, E. (1995). Effective Systems Design and Requirements Analysis: The ETHICS Approach. London: Macmillan.

Mumford, E., and Henshall, D. (1983). Designing Participatively: A Participative Approach to Computer Systems Design. Manchester, England: Manchester Business School.

Mumford, E., and MacDonald, B. (1990). XSEL's Progress: The Continuing Journey of an Expert System. Chichester, England: Wiley.

Murray, F., and Willmott, H. (1991). "The Communication Problem in Information Systems Development: Toward a Relational Approach." In J. I. DeGross, I. Benbasat, G. DeSanctis, and C. M. Beath (Editors), Proceedings of the Twelfth International Conference on Information Systems. New York, December, pp. 8392.

Naur P., and Randell, B. (1969). Software Engineering: Report on a Conference Sponsored by the NATO Science Committee, Garmisch, October, 1968. Brussels: NATO.

Westrup, C. (1996). Requirements Analysis: In Theory and Practice. UNpublished $\mathrm{Ph}, \mathrm{D}$. Thesis, UMIST, England.

Willmott, H.; Mouritsen, J.; Flensburg, P.; and Elkjaer, B. (1990). "Systems Developers: Preoccupations, Knowledge and Power." In J. I. DeGross, M. Alavi, and H. Oppelland (Editors), Proceedings of the Eleventh International Conference on Information Systems. Copenhagen, December, pp. 257-264.

Woolgar, S. (1991). "Configuring the User: The Case of Usability Trials." In J. Law (Editor), A Sociology of Monsters: Essays on Power, Technology and Domination. London: Routledge.

Woolgar, S. (1994). "Rethinking Requirements Analysis: Some Implications Research into Producer-Consumer Relationships in IT Development." In M. Jirotk and J. Groguen (Editors), Requirements Engineering: Social and Technical Issues. London: Academic Press, pp. 201-217.

\section{BIOGRAPHY}

Christopher Westrup is a lecturer at the Manchester School of Accounting and Finance at the University of Manchester. His interests are in the interrelationship between advanced information systems and organizations both in their development and their use. 